\title{
PRODUÇÃO DE POLI(3-HIDROXIBUTIRATO) por Cupriavidus necator UTILIZANDO VINHAÇA COMO SUBSTRATO
}

\author{
K. ZANFONATO ${ }^{1}$, C. S. GAI ${ }^{1}$, L. K. M. QUINES ${ }^{1}$, M. SCHMIDT ${ }^{1}$, F. M. MARTINHAGO ${ }^{1}$, W. \\ SCHMIDELL ${ }^{1}$ e G. M. F. ARAGÃO
}

${ }^{1}$ Universidade Federal de Santa Catarina, Departamento de Engenharia Química e Engenharia de Alimentos

E-mail para contato: glaucia@enq.ufsc.br

\begin{abstract}
RESUMO - Dentre os biopolímeros biodegradáveis, o mais estudado é o polihidroxibutirato $(\mathrm{P}(3 \mathrm{HB}))$ em função de suas propriedades similares às do polipropileno. Um dos principais obstáculos para sua produção é o elevado custo, e isto tem estimulado a procura por substratos de baixo custo. A vinhaça representa o principal resíduo do setor sucroenergético, pois são produzidos em torno de 12 litros deste subproduto a cada litro de etanol. $\mathrm{O}$ objetivo deste trabalho foi avaliar a produção de $\mathrm{P}(3 \mathrm{HB})$ por $C$. necator, a partir de vinhaça. O cultivo foi realizado em frasco erlenmeyer $\left(35^{\circ} \mathrm{C} / 150 \mathrm{rpm}\right)$, inicialmente com $200 \mathrm{ml}$ de vinhaça adicionada de sais e micronutrientes e, ao final da fase exponencial de crescimento, $200 \mathrm{~mL}$ de vinhaça pura foram adicionados na forma de pulso para aumentar a disponibilidade de substrato no meio. A concentração final de biomassa foi de $2,5 \mathrm{~g} / \mathrm{L}$ e o acúmulo de $\mathrm{P}(3 \mathrm{HB})$ foi $33 \%$. Com este resultado, foi possível verificar a capacidade de $C$. necator produzir $\mathrm{P}(3 \mathrm{HB})$ a partir de vinhaça.
\end{abstract}

\section{INTRODUÇÃO}

Dentre os biopolímeros biodegradáveis, os poli-hidroxialcanoatos (PHAs) são os mais estudados, pois são completamente biocompatíveis, biossintetizados e biodegradáveis, sendo o mais conhecido o poli(3-hidroxibutirato) $(\mathrm{P}(3 \mathrm{HB}))$, particularmente em função de suas propriedades similares às do polipropileno. Dentre os mais de 300 diferentes microrganismos capazes de sintetizar PHAs (Hazer e Steinbuchel, 2007), destaca-se a bactéria Cupriavidus necator (também conhecida como Ralstonia eutropha ou Alcaligenes eutrophus) pela capacidade de produzir elevadas porcentagens de PHAs e assimilar diferentes fontes de carbono (Lee, 1996).

Um dos principais obstáculos da produção de PHAs é seu elevado custo. Este inconveniente tem estimulado a procura por substratos de baixo custo, uma vez que em torno de $40 \%$ desses custos de produção estão relacionados à fonte de carbono utilizada (Kim, 2000; Ramadas et al., 2009).

No processo de produção de etanol, a partir da cana-de-açúcar, após a fermentação, o caldo fermentado é submetido ao processo de destilação para a obtenção do produto final. Durante o processo de destilação, o corpo de fundo da coluna recebe o nome de vinhaça, ou vinhoto. Tanto do ponto de vista qualitativo quanto quantitativo, a vinhaça representa a principal água residuária do setor sucroenergético, uma vez que é produzida na proporção de aproximadamente 12 litros 
para cada litro de etanol produzido pelos processos convencionais de fermentação utilizados no Brasil (Unica, 2013). A valorização da vinhaça, pelo desenvolvimento de um processo que utilize este resíduo como substrato para obtenção de um produto com alto valor agregado, como os biopolímeros biodegradáveis, contribui com valor adicional à produção de etanol, além de minimizar um problema ecológico e ambiental referente ao descarte deste resíduo.

A vinhaça é uma fonte de carbono de baixo custo e com potencial para ser utilizada na produção de PHAs, pois os principais componentes orgânicos presentes na vinhaça de cana-deaçúcar são o glicerol, ácido lático, etanol e ácido acético (Parnaudeau et al., 2008). A literatura relata vários casos de utilização destes substratos por microrganismos (Kapdan e Kargi, 2006; Silva et al., 2011).

Neste contexto, o objetivo deste trabalho foi avaliar a produção de $\mathrm{P}(3 \mathrm{HB})$ por de $C$. necator, a partir de vinhaça.

\section{MATERIAL E MÉTODOS}

\subsection{Preparo da Vinhaça}

A vinhaça utilizada nos experimentos foi obtida junto à Usina Iracema, no município de Iracemápolis/SP, coletada diretamente das colunas de destilação. As amostras foram acondicionadas em recipientes plásticos de $5 \mathrm{~L}$ e transportadas para a Universidade Federal de Santa Catarina (UFSC), onde foram congeladas permanecendo desta forma até o momento da sua utilização.

As análises de nitrogênio total, açúcares redutores totais e demanda química de oxigênio foram realizadas conforme metodologias analíticas descritas nas seções a seguir. A quantificação dos cloretos (realizada por eletrodo de íon seletivo); sulfatos (realizada por gravimetria); $\mathrm{Ca}, \mathrm{Fe}$, $\mathrm{Mn}, \mathrm{Mg}, \mathrm{Cu}, \mathrm{Zn}$ (realizada por absorção atômica); K (realizada por emissão atômica) e Na (realizada por fotometria de chama) foram feitas na Central de Análises - Departamento de Química da UFSC.

Antes de cada experimento, a vinhaça passou por tratamentos que incluíram o ajuste do $\mathrm{pH}$ para 7,0 (através da adição de $\mathrm{NaOH} 2,5 \mathrm{~N}$ ) e esterilização por filtração em sistema com membrana tubular, capilar, de polipropileno, autoclavável, modelo MD020 CP 2N (Mycrodin Nadir, FRINGS DO BRASIL Engenharia e Comércio Ltda, Piracicaba - SP), com diâmetro de poro igual a $0,2 \mu \mathrm{m}$ e área de filtração de $0,1 \mathrm{~m}^{2}$.

\subsection{Microrganismo, Meio e Condições de Cultivo}

Microrganismo: O microrganismo utilizado foi a bactéria Cupriavidus necator DSM 545, mantida em glicerol a $-80^{\circ} \mathrm{C}$.

Pré-cultura: $\mathrm{O}$ meio de cultura utilizado para a reativação da cepa (armazenada a $-80{ }^{\circ} \mathrm{C}$ ) foi o Nutrient Broth (NB), com a seguinte composição: $5 \mathrm{~g} / \mathrm{L}$ de peptona de carne e $3 \mathrm{~g} / \mathrm{L}$ de extrato de carne. 
Cultivo para verificar o crescimento de $C$. necator em vinhaça: Para verificar se haveria inibição do crescimento de $C$. necator em vinhaça, diferentes concentrações deste substrato foram testadas $(0,5 ; 5 ; 10$ e $100 \%$ v/v) em meio mineral. A composição do meio mineral (descrito por Aragão et al. (1996) com modificações) utilizado foi (em g/L): $\mathrm{KH}_{2} \mathrm{PO}_{4} 1$, citrato de amônio e ferro III 0,06, $\mathrm{CaCl}_{2} \cdot 2 \mathrm{H}_{2} \mathrm{O} 0,01, \mathrm{MgSO}_{4} \cdot 7 \mathrm{H}_{2} \mathrm{O} 0,5$, ureia 2, ácido nitrilotriacético 0,19 e elementos traço $1 \mathrm{~mL} / \mathrm{L}$. A solução de elementos traço teve a seguinte composição (em g/L) $\mathrm{H}_{3} \mathrm{BO}_{3} 0,3$, $\mathrm{CoCl}_{2} \cdot 6 \mathrm{H}_{2} \mathrm{O} 0,2, \mathrm{ZnSO}_{4} \cdot 7 \mathrm{H}_{2} \mathrm{O} 0,1, \mathrm{MnCl}_{2} \cdot 4 \mathrm{H}_{2} \mathrm{O} 0,03, \mathrm{Na}_{2} \mathrm{MoO}_{4} \cdot 2 \mathrm{H}_{2} \mathrm{O} \quad 0,03, \mathrm{NiCl}_{2} \cdot 6 \mathrm{H}_{2} \mathrm{O} 0,02 \mathrm{e}$ $\mathrm{CuSO}_{4} .5 \mathrm{H}_{2} \mathrm{O}$ 0,01. Primeiramente, uma pré-cultura conduzida em frasco erlenmeyer aletado de $500 \mathrm{~mL}$, com $150 \mathrm{~mL}$ de volume útil, incubada por $18 \mathrm{~h}\left(150 \mathrm{rpm} / 35^{\circ} \mathrm{C}\right)$, contendo $\mathrm{NB}$ foi realizada. Esta serviu como inóculo $(10 \% \mathrm{v} / \mathrm{v})$ para os testes qualitativos com diferentes concentrações de vinhaça, que foram realizados em frascos erlenmeyers aletados de $250 \mathrm{~mL}$, mantidos a $35^{\circ} \mathrm{C}$ e $150 \mathrm{rpm}$, com $100 \mathrm{~mL}$ de meio.

Cultivo para avaliar o crescimento e produção de $\mathrm{P}(3 \mathrm{HB})$ em vinhaça: Para analisar o crescimento e acúmulo de polímero por $C$. necator em vinhaça, foi realizado um cultivo a partir de duas pré-culturas, a primeira conduzida em frasco erlenmeyer aletado de $500 \mathrm{~mL}$, com $150 \mathrm{~mL}$ de volume útil, incubada por $18 \mathrm{~h}\left(150 \mathrm{rpm} / 35^{\circ} \mathrm{C}\right)$, contendo $\mathrm{NB}$, e a segunda conduzida em erlenmeyer aletado de $1000 \mathrm{~mL}, 200 \mathrm{~mL}$ de volume útil, contendo vinhaça (100\%) em meio mineral, incubada sob as mesmas condições da primeira. Esta segunda pré-cultura foi utilizada a uma concentração de $10 \%$ (v/v) para os cultivos.

O cultivo apresentado neste trabalho iniciou com volume útil de $200 \mathrm{~mL}$ em erlenmeyer aletado de $1000 \mathrm{~mL}$ (vinhaça em meio mineral $+0,2 \mathrm{~g}_{\mathrm{N}} / \mathrm{L}$ ) e após 7 horas um volume de $200 \mathrm{~mL}$ de vinhaça pura foi adicionado na forma de pulso.

\subsection{Determinações Analíticas}

Amostragem: Amostras foram retiradas para o acompanhamento do crescimento da biomassa por espectrofotometria a $600 \mathrm{~nm}$ e determinação da concentração celular por gravimetria. Nas amostragens, $2 \mathrm{~mL}$ de meio de cultivo foram coletados em microtubos de plástico e centrifugados a $14000 \mathrm{rpm}$ por $3 \mathrm{~min}$, em seguida lavados os precipitados com $1 \mathrm{~mL}$ de água destilada, centrifugados mais uma vez, sendo congelados os sobrenadantes e precipitados. $\mathrm{O}$ sobrenadante foi posteriormente utilizado para a análise do consumo de substrato e o precipitado para análise de determinação de $\mathrm{P}(3 \mathrm{HB})$.

Massa celular seca: A biomassa foi determinada por gravimetria após filtração, em membrana de poro $0,2 \mu \mathrm{m}$, de um volume conhecido $(5 \mathrm{~mL})$ de cultura seguida de secagem em estufa $\left(100^{\circ} \mathrm{C}\right)$, durante 24 horas.

Concentração de ART e nitrogênio: A determinação de açúcares redutores totais (ART) foi realizada pelo método do ácido 3-5 dinitrosalicílico (DNS) (Miller, 1959). O nitrogênio foi determinado utilizando-se o kit Uréia ES (Gold Analisa), que determina a concentração de ureia pelo método enzimático-colorimétrico.

Concentração de $\mathrm{P}(3 \mathrm{HB})$ : As células contendo $\mathrm{P}(3 \mathrm{HB})$ foram analisadas por HPLC, segundo Karr et al. (1983), com modificações. Esta análise foi realizada em equipamento Jasco (LC-2000Plus Series). A concentração de P(3HB) foi detectada a 210 nm (Jasco UV-2077). 
Determinação da Demanda Química de Oxigênio (DQO): Análise foi realizada segundo o procedimento do Standart Methods for the Examination of Water and Wastewater (1995).

\subsection{Tratamento dos Dados}

Uma vez que o acúmulo de $\mathrm{P}(3 \mathrm{HB})$ é intracelular, as velocidades específicas de crescimento celular foram calculadas em relação à biomassa residual $(\mathrm{Xr})$, obtida pela diferença entre a quantidade de biomassa total (Xt) e a quantidade de $\mathrm{P}(3 \mathrm{HB})(\mathrm{Xr}=\mathrm{Xt}-\mathrm{P}(3 \mathrm{HB}))$. Realizou-se um ajuste polinomial aos dados experimentais obtidos através do software Microsoft Office Excel 2007. A análise cinética dos resultados obtidos foi realizada através dos ajustes das curvas de biomassa total $(\mathrm{Xt})$, biomassa residual $(\mathrm{Xr}), \mathrm{P}(3 \mathrm{HB})(\mathrm{P})$ versus o tempo, também pelo Microsoft Office Excel 2007.

A partir dos perfis de concentração de $\mathrm{Xr}$, foi possível determinar, em cada instante, as velocidades instantâneas de crescimento $(\mathrm{dXr} / \mathrm{dt})$. Dividindo-se as velocidades instantâneas pela concentração celular $(\mathrm{Xr})$ no instante $\mathrm{t}$, a velocidade específica $\left(\mu_{\mathrm{Xr}}\right)$ foi obtida.

\section{RESULTADOS E DISCUSSÃO}

\subsection{Composição da vinhaça}

Na Tabela 1, é apresentada a composição química da vinhaça utilizada neste estudo, coletada em maio de 2013.

Tabela 1 - Composição química da vinhaça utilizada neste trabalho

\begin{tabular}{cc}
\hline Parâmetros & Vinhaça \\
\hline $\mathrm{pH}$ & 4,4 \\
DQO $(\mathrm{mg} / \mathrm{L})$ & 22700 \\
Nitrogênio $(\mathrm{g} / \mathrm{L})$ & 0,03 \\
Açúcares redutores totais $(\mathrm{g} / \mathrm{L})$ & 3,2 \\
Glicerol $(\mathrm{g} / \mathrm{L})$ & 4,6 \\
Cloretos $(\%)$ & 0,158 \\
Sulfatos $(\%)$ & 0,096 \\
Ca total $(\mathrm{mg} / \mathrm{L})$ & 578 \\
Fe total $(\mathrm{mg} / \mathrm{L})$ & 23,2 \\
Mn total $(\mathrm{mg} / \mathrm{L})$ & 3,21 \\
Mg total $(\mathrm{mg} / \mathrm{L})$ & 138,8 \\
Cu total $(\mathrm{mg} / \mathrm{L})$ & 0,66 \\
Zn total $(\mathrm{mg} / \mathrm{L})$ & 0,43 \\
K total $(\mathrm{g} / \mathrm{L})$ & 1,2 \\
Na total $(\mathrm{mg} / \mathrm{L})$ & 75 \\
\hline
\end{tabular}

Ao analisar comparativamente os resultados da composição química da vinhaça utilizada neste trabalho com os dados presentes na literatura, foi possível notar que os parâmetros da composição da vinhaça estão dentro ou próximos aos limites de variação (España-Gamboa et al., 2011; González et al., 2012). A composição química da vinhaça é bastante variável e depende, principalmente, de fatores como a natureza e a composição da matéria prima, do sistema usado no 
preparo do mosto, do método de fermentação adotado e do sistema de condução da fermentação alcoólica, do tipo de levedura utilizada, do tipo de destilador empregado e da maneira de destilação (Gloria e Orlando Filho, 1984).

\subsection{Ensaios qualitativos do crescimento de $C$. necator em vinhaça}

Conforme Bekatorou et al. (2006), uma das vantagens da utilização da vinhaça em processos biotecnológicos é a mesma ser livre de toxinas e inibidores de fermentação. Por outro lado, Santos et al. (2003) afirmaram que a presença de alguns compostos, como os fenólicos, podem ser tóxicos e/ou inibir o crescimento de microrganismos.

A análise qualitativa do crescimento de $C$. necator foi realizada neste trabalho com objetivo de verificar uma possível inibição do crescimento desta bactéria causada pelos componentes da vinhaça. Os resultados obtidos nestes ensaios preliminares demonstraram que, sob as condições testadas, foi verificado crescimento da biomassa em todas as concentrações de vinhaça $(0,5 ; 5 ; 10$ e $100 \%)(\mathrm{v} / \mathrm{v})$.

\subsection{Ensaios para analisar o crescimento e produção de $\mathbf{P}(3 \mathrm{HB})$ por $C$. necator}

O cultivo realizado para produção de $\mathrm{P}(3 \mathrm{HB})$ foi conduzido em batelada alimentada em vinhaça com adição de sais e com adição de vinhaça pura (sem adição de sais) na forma de pulso, ao final da fase exponencial de crescimento. Em análise cinética do crescimento de $C$. necator em vinhaça realizada em trabalhos anteriores, determinou-se que o tempo de incubação até o final da fase exponencial de crescimento foi de aproximadamente 7 horas, $\left(35^{\circ} \mathrm{C} / 150 \mathrm{rpm}\right)$. Além disso, observou-se uma baixa concentração de biomassa, indicando provavelmente a insuficiência de fontes de carbono na vinhaça que permitiriam uma maior concentração final de biomassa (Dos Santos et al., 2013).

As curvas de biomassa total, biopolímero e biomassa residual são mostradas na Figura 1. Estes dados estão expressos em massa (g) e não em concentração, em função da variação de volume do ensaio. Na Figura 2, são apresentados os dados referentes às concentrações residuais de nitrogênio e DQO (a) e ART (b). 


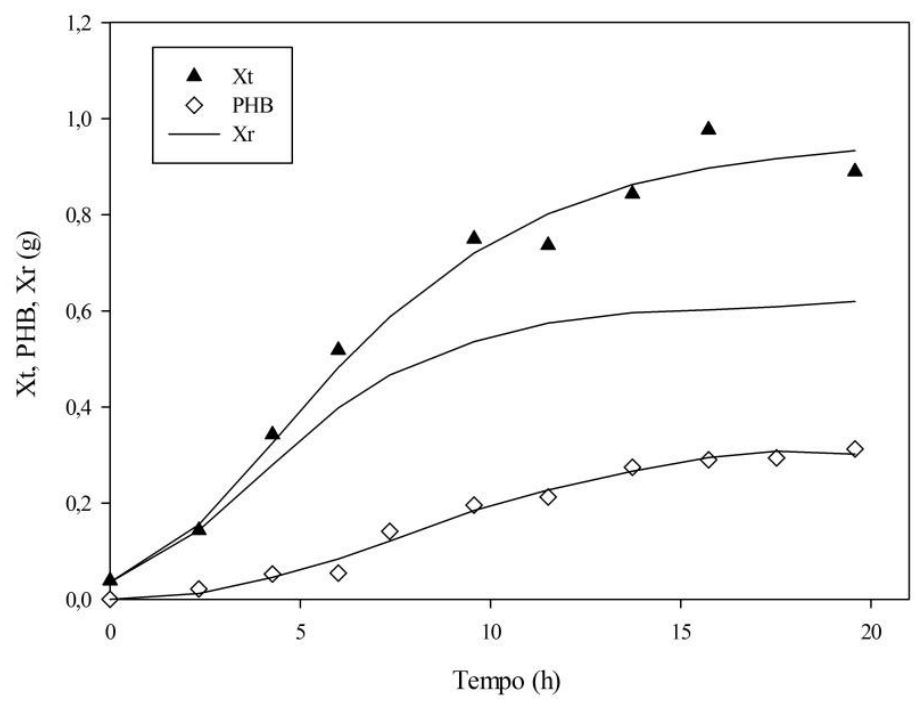

Figura 1 - Evolução de biomassa total $(\mathrm{Xt}(\boldsymbol{\Delta}))$, biomassa residual $(\mathrm{Xr}(-))$ e $\mathrm{P}(3 \mathrm{HB})(\diamond)$ para $C$. necator em incubador rotativo, para o cultivo com adição de vinhaça através de pulso após 7 horas de cultivo.
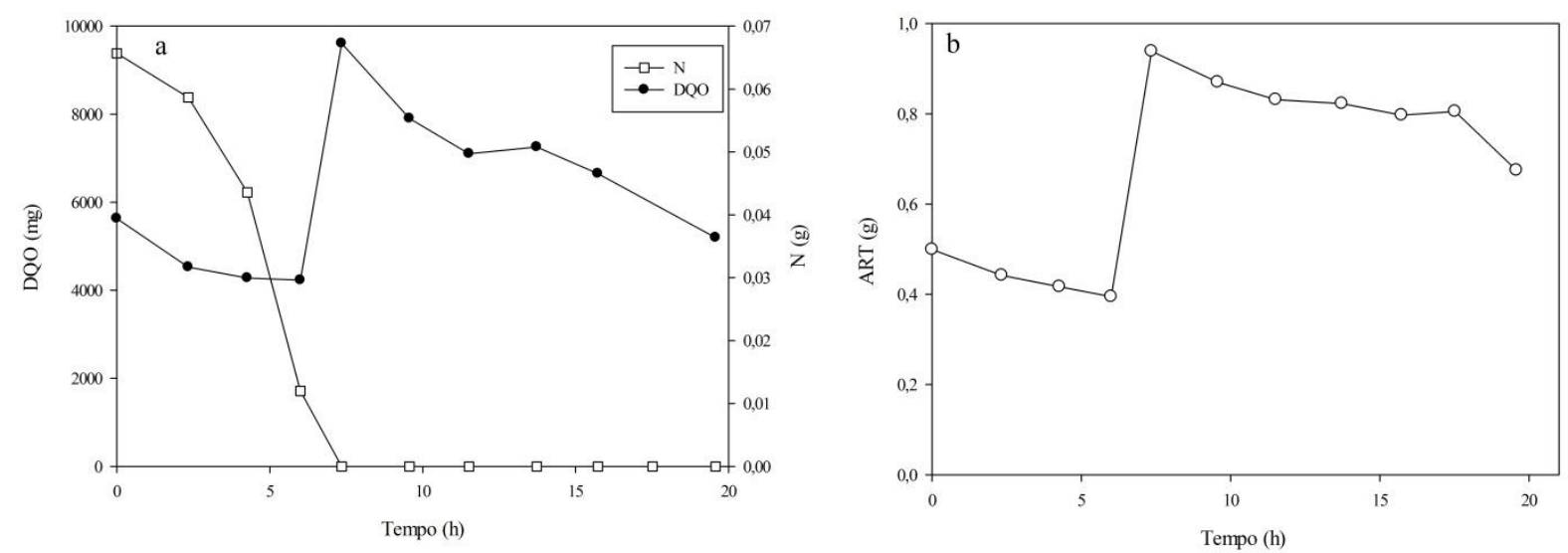

Figura 2 - (a) Concentração residual de nitrogênio (N ( $\square$ )) e de DQO (•) ao longo do tempo; (b) Concentração residual de açúcares redutores totais ao longo do tempo para o cultivo com adição de vinhaça através de pulso após 7 horas de cultivo.

A biomassa celular final (Xt) foi de aproximadamente $1 \mathrm{~g}$ e a biomassa residual praticamente cessou o crescimento no instante $7 \mathrm{~h}$, momento em que a concentração de nitrogênio encontrava-se próxima a zero, uma vez que esse nutriente é essencial para o crescimento da bactéria $C$. necator. A velocidade específica máxima de crescimento neste cultivo foi de $0,40 \mathrm{~h}^{-1}$, valor este superior ao encontrado por Schmidt (2011) $\left(0,26 \mathrm{~h}^{-1}\right)$, que avaliou a produção de $\mathrm{P}(3 \mathrm{HB})$ com o mesmo microrganismo em cultivos também em frascos agitados, utilizando como fonte de carbono glicose e frutose (concentração inicial de $40 \mathrm{~g} / \mathrm{L}$ ).

O acúmulo máximo de $\mathrm{P}(3 \mathrm{HB})$ foi $33 \%(\mathrm{~m} / \mathrm{m})$, este acúmulo foi melhor percebido quando a quantidade de nitrogênio foi igual ou menor a 0,04 g (aproximadamente $0,20 \mathrm{~g} / \mathrm{L}$ ) que ocorreu em torno de 7 horas, ou seja, ligeiramente antes do momento do pulso de vinhaça. A produção de biopolímero parece ter cessado com 16 horas de ensaio, apesar da disponibilidade de substrato (matéria orgânica), como demonstrado na quantificação da DQO residual. A DQO presente no meio foi consumida até em torno de $5 \mathrm{~g}$ (por volta de $12 \mathrm{~g} / \mathrm{L}$ ), demonstrando um consumo com 
caráter linear, como pode ser visto na Figura 2 (a). Assim como o residual de material orgânico, ao final do cultivo ainda havia ART disponível no meio, como mostrado na Figura 2 (b).

Pramanik et al. (2012) utilizaram vinhaça para a produção de $\mathrm{P}(3 \mathrm{HB})$ a partir de Haloarcula marismortui, um microrganismo halofílico (capaz de crescer em elevadas concentrações de sais) e o acúmulo final de $\mathrm{P}(3 \mathrm{HB})$ em meio contendo $10 \%$ (v/v) de vinhaça foi de $30 \%(\mathrm{~m} / \mathrm{m})$ com $\mu_{\text {Xrmax }}$ de $0,086 \mathrm{~h}^{-1}$. É importante ressaltar que, apesar do acúmulo de $\mathrm{P}(3 \mathrm{HB})$ do cultivo apresentado neste trabalho, com estratégia de pulso e limitação em nitrogênio assim como para os autores citados, ter ficado em torno de $30 \%$, este trabalho utilizou um microrganismo não halofílico e as concentrações de vinhaça avaliadas foram superiores (até 100 $\%$ ), demonstrando que a bactéria abordada neste estudo, apesar de não ser um microrganismo halofílico, foi capaz de crescer e produzir $\mathrm{P}(3 \mathrm{HB})$ em meio de cultivo contendo elevadas concentrações de vinhaça.

\section{CONCLUSÕES}

Os experimentos em caráter qualitativo realizados, para verificar uma possível inibição no crescimento de $C$. necator DMS 545 em vinhaça, permitiram verificar que esta bactéria é capaz de crescer utilizando este substrato nas concentrações de vinhaça estudadas, chegando a $100 \%$ (v/v). Os dados obtidos permitem concluir que $C$. necator DMS 545 foi capaz de produzir $\mathrm{P}(3 \mathrm{HB})$ a partir de vinhaça, com percentual de acúmulo em torno de $30 \%(\mathrm{~m} / \mathrm{m})$.

\section{REFERENCIAS}

APHA, AWWA, WEF. Standard methods for the examination of water and wastewater $19^{\text {th }}$. American public health association. Washington, DC, 1995.

ARAGÃO, G.M.F.; LINDLEY, N.D.; URIBELARREA, J.L.; PAREILLEUX, A. Maintaining a controlled residual growth capacity increases the production of polyhydroxyalkanoate copolymers by Alcaligeneseutrophus. Biotechnol.Lett., v. 18, p. 937-942, 1996.

BEKATOROU, A.; PSARIANOS, C.; KOUTINAS, A. Production of food grade yeasts.Food Technol.Biotechnol., v. 44, p. 407-415, 2006.

DOS SANTOS, E.; GAI, C.; ZANFONATO, K.; MARTINHAGO, F.; STEFFEN, W.; QUINES L.K.; SCHMIDT, M.; SCHMIDELL, W.; ARAGÃO, G.M.F. Production of polyhydroxyalkanoate biopolymer from vinasse using Ralstonia eutropha. $5^{\circ}$ Congresso Brasileiro de Biotecnologia. Florianópolis, 2013.

ESPAÑA-GAMBOA, E.; MIJANGOS-CORTES, J.; BARAHONA-PEREZ, L.; DOMINGUEZMALDONADO, J.; HERNÁNDEZ-ZARATE, G.; ALZATE-GAVIRIA, L. Vinasse: characterization and treatments. WasteManage., 29, 1235-1250, 2011.

GLORIA, N.A.; ORLANDO FILHO, J. Aplicação de vinhaça: um resumo e discussões sobre o que foi pesquisado. Álcool e Açúcar,São Paulo, v. 4, n. 15, p. 22 - 31, 1984.

GONZALEZ, V.R.; MAYER, J.G.; SEIJAS, N.R.; VARALDO, H.M.P. Treatment of mezcalvinasses: A review. J. Biotechnol., v. 157, p. 524-546, 2012. 
HAZER, B.; STEINBUCHEL, A. Increased diversification of polyhydroxyalkanoates by modification reactions for industrial and medical applications.Appl.Microbiol. Biotechnol., v. 74, p. 1-12, 2007.

KAPDAN, K.I.; KARGI, F. Review Bio-hydrogen production from waste materials. Enzyme Microb. Technol., v. 38 (5), p. 569-582, 2006.

KARR, D.B.;WATERS,J.K;EMERICH, D.W. Analysis of Poly-3-Hydroxybutyrate in Rhizobium japonicum bacteroids by ion-exclusion high-pressure liquid chromatography and UV detection. App Environ.Microbiol., v. 46 (6), p. 1339-1344, 1983.

KIM, B.S. Production of poly(3-hydroxybutyrate) from inexpensive substrates. Enzyme Microbiol Technol., v. 27 (10), p. 774-777, 2000.

LEE, S.Y. Plastic bacteria - progress and prospects for polyhydroxyalcanoate production in bacteria. Trends Biotechnol., v. 14, p. 437 - 438, 1996.

PARNAUDEAU, V.; CONDON, N.; OLIVER, R.; CAZEVIEILLE, P.; RECOUS, S. Vinasse organic matter quality and mineralization potential, as influenced by raw material, fermentation and concentration processes. Bioresour.Technol., v. 99, p. 1553-1562, 2008.

PRAMANIK, A.; MITRA, A.; ARUMUGAM, M.; BHATTACHARYYA, A.; SADHUKHAN, S.; RAY, A.; HALDAR, S.; MUKHOPADHYAY, U.K.; MUKHERJEE, J. Utilization of vinasse for the production of polyhydroxybutyrate by Haloarcula marismortui. Folia Microbiol., v. 57, p. 71- 79, 2012.

RAMADAS, N.V.; SINGH, S.K.; SOCCOL, C.R.; PANDEY, A. Polyhydroxybutyrate production using agro-industrial residue as substrate by Bacillus sphaericus NCIM 5149. Braz. Arch. Biol. Technol., v. 52(1), p. 17-23, 2009.

SANTOS, M.A.M.; BOCANEGRA, J.L.F.; MARTÍN, A.M.; GARCÍA, I.G. Ozonation of vinasse in acid and alkaline media.J. Chem.Technol.Biotechnol., v. 78, p. 1121-1127, 2003.

SCHMIDT, M. Produção de poli(3-hidroxibutirato) por Cupriavidus necator DSM 545 em meio suplementado com óleo de soja miniemulsionado. Florianópolis. Dissertação de Mestrado (Engenharia de Alimentos). Universidade Federal de Santa Catarina,2011.

SILVA, C.F.; ARCURI, S.L.; CAMPOS, C.R.; VILELA, D.M.; ALVES, J.G.L.F.; SCHWAN, R.F. Using the residue of spirit production and bio-ethanol for protein production by yeasts. Waste Manegem. v. 31, p. 108-114, 2011.

UNICA - União da Indústria da Cana-de-Açúcar - http://www.unica.com.br/ Acesso em fevereiro de 2014. 